

Submitted: 26 Mar 2018 Accepted: 11 Nov 2018 Online: 28 Dec 2018

\section{A Review on Sample Size Determination for Cronbach's Alpha Test: A Simple Guide for Researchers}

\author{
Mohamad Adam Bujang', Evi Diana Omar², Nur Akmal Baharum³ \\ Clinical Research Centre, Sarawak General Hospital, Ministry of Health, \\ Sarawak, Malaysia \\ 2 Clinical Research Centre, Serdang Hospital, Ministry of Health, \\ Selangor, Malaysia \\ 3 National Clinical Research Centre, Ministry of Health, Kuala Lumpur, \\ Malaysia
}

To cite this article: Mohamad Adam B, Evi Diana O, Nur Akmal B. A review on sample size determination for Cronbach's alpha test: a simple guide for researchers. Malays J Med Sci. 2018;25(6):85-99. https://doi.org/10. 21315/mjms2018.25.6.9

To link to this article: https://doi.org/10.21315/mjms2018.25.6.9

\title{
Abstract
}

Background: Reliability studies are commonly used in questionnaire development studies and questionnaire validation studies. This study reviews the sample size guideline for Cronbach's alpha test.

Methods: Manual sample size calculation using Microsoft Excel software and sample size tables were tabulated based on a single coefficient alpha and the comparison of two coefficients alpha.

Results: For a single coefficient alpha test, the approach by assuming the Cronbach's alpha coefficient equals to zero in the null hypothesis will yield a smaller sample size of less than 30 to achieve a minimum desired effect size of o.7. However, setting the coefficient of Cronbach's alpha larger than zero in the null hypothesis could be necessary and this will yield larger sample size. For comparison of two coefficients of Cronbach's alpha, a larger sample size is needed when testing for smaller effect sizes.

Conclusions: In the assessment of the internal consistency of an instrument, the present study proposed the Cronbach's alpha's coefficient to be set at 0.5 in the null hypothesis and hence larger sample size is needed. For comparison of two coefficients' of Cronbach's alpha, justification is needed whether testing for extremely low and extremely large effect sizes are scientifically necessary.

Keywords: Cronbach's alpha, internal consistency, reliability, sample size

\section{Introduction}

Cronbach's alpha is a measure of the internal consistency or reliability between several items, measurements or ratings. In other words, it estimates how reliable are the responses of a questionnaire (or domain of a questionnaire), an instrumentation or rating evaluated by subjects which will indicate the stability of the tools. Alpha was developed by Cronbach (1), which was originally used to measure the reliability of a psychometric instrument. The value of Cronbach's alpha ranges from zero to one with the higher values implying the items are measuring the same dimension. In contrary, if the Cronbach's alpha value is low (near to o), it means some or all of the items are not measuring the same dimension (2-3). 
For example, the Depression Anxiety and Stress Scale (DASS-21) that is used to measure the magnitude of respondents' stress level condition for over the past week, has seven items measured by using a four-point Likert scale (ranging from zero to three) (4). To ascertain whether the items are reliable in measuring the same dimension, a test for Cronbach's alpha may be used. The Cronbach's alpha test is usually applied to test the consistency and stability of the questionnaires which measure latent variables. Although Cronbach's alpha test may be applied in situations other than questionnaire development or validation, there is limited literature of its application in such scenarios.

Cronbach's alpha has been applied in research to develop clinical tool. For instance, a study by Berg et al. (5) developed an instrument to measure the balancing ability in elderly patients. The study used a scale consisting of 14 movements of patients such as sitting unsupported, change of position and etc. The movements were evaluated by five physical therapists and they were given a score from zero to four for each movement. The high degree of internal consistency in this study showed that the scale measures the same dimension

One of the common issues in inferential studies is to determine the sufficient sample size. The lack of knowledge in sample size determination and unfamiliarity with sample size softwares are usually the challenges encountered by researchers especially among those who do not have adequate knowledge in statistics. Sufficient sample size is needed so that research conducted can provide reliable and reproducible evidence that can detect the desired consistency or stability of an instrument (questionnaire). It is an important aspect in research to avoid lack of power of the test due to underestimation of sample size and also prevent the waste of resources due to overestimation of sample size (6).

The purpose of this present paper is to provide a simple guide for medical researchers to plan sample size estimation for their studies that involve Cronbach's alpha test. The sample sizes are determined and presented in the form of tables to estimate the minimum number of samples needed to obtain the desired value of Cronbach's alpha. Following that, the discussion of this paper emphasizes on the application of the formula and the sample size tables.

\section{Cronbach's Alpha Test}

Discussion on Cronbach's alpha test in terms of concept, applications, statistical test and sample size determination have been widely discussed in the literatures $(7-11)$. Some of the discussions related to sample size are summarised in Table $1(6,12-16)$. The present study emphasizes the review of sample size determination for Cronbach's alpha and focuses on sample size determination introduced by Bonett $(6,12)$.

\section{Hypothesis Testing for a Single Cronbach's Alpha Test}

The null hypothesis is $\mathrm{H}_{0}$ : $\mathrm{CAO}=\mathrm{CA} 1$ and the possible selection of alternative hypotheses are:

$$
\begin{aligned}
\mathrm{H}_{\mathrm{a}}: & \text { CAo } \neq \text { CA1 (this option yields a } \\
& \text { two-tailed test) } \\
\mathrm{H}_{\mathrm{a}}: & \text { CAo }<\text { CA1 (this option yields a } \\
& \text { one-tailed test) } \\
\mathrm{H}_{\mathrm{a}}: & \text { CAo }>\text { CA1 (this option also yields } \\
& \text { a one-tailed test) }
\end{aligned}
$$

CAo refers to the value of Cronbach's alpha in null hypothesis and CA1 refers to the value of Cronbach's alpha in alternative hypothesis. Most commonly CAo is assumed and set at $\mathrm{o}$ in which smaller sample sizes are derived since the gap between CAO and CA1 is larger. Setting up the CAo as not equal to $\mathrm{O}$ is uncommon in research but it is very useful in testing and comparing the hypothesis of two different alpha coefficients (13).

\section{Hypothesis Testing for Comparison of Two Cronbach's Alpha Test}

The null hypothesis is $\mathrm{H}_{\mathrm{o}}: \rho_{a}=\rho_{b}$ and the possible selection of alternative hypotheses are:

$$
\begin{aligned}
\mathrm{H}_{\mathrm{a}}: & \begin{array}{l}
\rho_{a} \neq \rho_{b} \text { (this option yields a two- } \\
\text { tailed test) }
\end{array} \\
\mathrm{H}_{\mathrm{a}}: & \rho_{a}<\rho_{b} \text { (this option yields a one- } \\
\text { tailed test) } & \\
\mathrm{H}_{\mathrm{a}}: & \begin{array}{l}
\rho_{a}>\rho_{b} \text { (this option also yields a } \\
\text { one-tailed test) }
\end{array}
\end{aligned}
$$

$\rho_{a}$ refers to the value of Cronbach's alpha in population "a" and $\rho_{b}$ refers to the value of Cronbach's alpha in population " $\mathrm{b}$ ". 
Original Article | Sample size for Cronbach's alpha

Table 1. The summarise on previous publication related sample size estimation for Cronbach's alpha

\begin{tabular}{|c|c|c|c|}
\hline No & Title & Author & Remarks \\
\hline 1 & $\begin{array}{l}\text { Sample size requirements for testing } \\
\text { and estimating coefficient alpha. }\end{array}$ & $\begin{array}{l}\text { Bonett DG } \\
(2002)\end{array}$ & $\begin{array}{l}\text { The sample size formulas closely approximate } \\
\text { the sample size requirements for an exact } \\
\text { confidence interval or an exact test. }\end{array}$ \\
\hline 2 & $\begin{array}{l}\text { Sample size requirements for } \\
\text { comparing two alpha reliability } \\
\text { coefficients }\end{array}$ & $\begin{array}{l}\text { Bonett DG } \\
(2003)\end{array}$ & $\begin{array}{l}\text { Introduce sample size determination for } \\
\text { comparing two alpha coefficients. }\end{array}$ \\
\hline 3 & $\begin{array}{l}\text { Minimum sample size for Cronbach's } \\
\text { coefficient alpha: a Monte Carlo }\end{array}$ & $\begin{array}{l}\text { Yurdugül H } \\
(2008)\end{array}$ & $\begin{array}{l}\text { This paper suggests the sample size of } \\
30 \text { is sufficient on condition that first } \\
\text { (largest) eigenvalue obtained from Principal } \\
\text { Component Analysis (PCA) of the sample } \\
\text { data set is higher than } 6.00 \text {. However, if that } \\
\text { first eigenvalues are between } 3.00 \text { and } 6.00 \text {, } \\
\text { then required minimum sample size is } 100 \text {. }\end{array}$ \\
\hline 4 & $\begin{array}{l}\text { Cronbach's alpha reliability: Interval } \\
\text { estimation, hypothesis testing, and } \\
\text { sample size planning }\end{array}$ & $\begin{array}{l}\text { Bonett DG, } \\
\text { Wright T } \\
(2015)\end{array}$ & $\begin{array}{l}\text { The results of a simulation studydemonstrated } \\
\text { that the proposed method performed better } \\
\text { than alternative methods. }\end{array}$ \\
\hline 5. & $\begin{array}{l}\text { Statistical methods-scale reliability } \\
\text { analysis with small samples, } \\
\text { Birmingham City University, } \\
\text { Centre for Academic Success }\end{array}$ & $\begin{array}{l}\text { Samuels P } \\
(2015)\end{array}$ & $\begin{array}{l}\text { Provides guideline for reliability analysis } \\
\text { considering small samples. }\end{array}$ \\
\hline 6. & $\begin{array}{l}\text { The RCSI sample size handbook: } \\
\text { a rough guide }\end{array}$ & $\begin{array}{l}\text { Conroy R } \\
(2016)\end{array}$ & $\begin{array}{l}\text { This study summarized that sample size of } \\
30 \text { can measure reliability using Cronbach's } \\
\text { alpha considering the scale items have strong } \\
\text { correlations. }\end{array}$ \\
\hline
\end{tabular}

\section{Methods}

\section{Sample Size Calculation Based on Formula by Bonett (6)}

Sample size for Coefficient alpha or Cronbach's alpha was calculated using Microsoft Excel. The formulation was from Bonett (6) based on formula given;

$$
n=\left[\left\{\left(\frac{2 k}{k-1}\right)\left(Z_{\alpha} / 2+Z_{\beta}\right)^{2}\right\} / \ln (\tilde{\delta})^{2}\right]+2
$$

where

$$
\delta=\frac{1-\mathrm{CAO}}{1-\mathrm{CA} 1}
$$

Sample size was calculated based on power of 0.80 and 0.90 (Power $=1-\beta$ ) while probability of type I error $(\alpha)$ was set at 0.05 at all time. There are options on whether to use two-tailed test or one-tailed test settings. In this paper, the more-commonly used two-tailed test was chosen with the aim to detect the difference between the two Cronbach's alpha. There are three things that need to be considered when determining the sample size for Cronbach's alpha test: the number of items or raters $(k)$, the value of Cronbach's alpha at null hypothesis (CAO) and the expected value of Cronbach's alpha (CA1). The value for CAo and CA1 could be any value ranges from -1 to 1 , however CA1 should not be equal to $\mathrm{CAO}(\mathrm{CA} 1 \neq \mathrm{CAO})$.

In order to illustrate the above formula with an example; there are 15 items in a questionnaire of which the reliability of its measurements need to be measured (CAo and CA1 are identified at 0.0 and 0.7 , respectively). Power is set at $90 \%$ and the value of alpha at 0.05 . The minimum sample size required based on formula (i) and (ii) is as shown below: 
Calculations:

$\alpha=0.05$

$\beta=0.1$

$k=15$

$\mathrm{CAO}=0.0$

$\mathrm{CA} 1=0.7$

$\delta=\frac{1-0.0}{1-0.7}=3.333$

$n=\left[\frac{\left\{\left(\frac{2(15)}{15-1}\right)\left(Z_{0.025}=1.96+Z_{0.1}=1.282\right)^{2}\right\}}{\ln (3.333)^{2}}\right]+2$

$n=17.53 \approx 18$

Therefore, the minimum sample size required for this case study is approximately 18 samples.

\section{Sample Size Calculation Based on Formula by Bonett (12)}

Sample size for comparing two Coefficient alpha or Cronbach's alpha was also calculated using Microsoft Excel. The formulation was from Bonett (12) based on formula given;

$$
n=\left[\frac{2\left(\frac{k 1}{k 1-1}+\frac{k 2}{k 2-1}\right)\left(Z_{\alpha / 2}+Z_{\beta}\right)^{2}}{\ln (\tilde{\delta})^{2}}\right]+2
$$

where

$$
\delta=\frac{\left(1-\rho_{a}\right)}{\left(1-\rho_{b}\right)}
$$

Sample size was calculated based on power of 0.80 and 0.90 (Power $=1-\beta$ ) while probability of type I error $(\alpha)$ was set at 0.05 at all time. There are options on whether to use two-tailed test or one-tailed test settings. In this paper, the more-commonly used two-tailed test was chosen with the aim to detect the difference between the two Cronbach's alpha. There are four things that need to be considered when determining the sample size for Cronbach's alpha test: the number of items or raters in group one $\left(k_{1}\right)$, the number of items or raters in group two $\left(k_{2}\right)$, the value of Cronbach's alpha at null hypothesis or group one $\left(\rho_{a}\right)$ and the expected or group two value of Cronbach's alpha $\left(\rho_{b}\right)$. The value of $k_{1}$ and $k_{2}$ are set to be similar and present as $k$. The value for $\rho_{a}$ and $\rho_{b}$ could be any value ranges from -1 to 1 , however $\rho_{b}$ should not be equal to $\rho_{a}\left(\rho_{b} \neq \rho_{a}\right)$. In order to illustrate the above formula with an example; there are ten items in a questionnaire in group 1 and 2 for which the reliability of its measurements need to be measured ( $\rho_{a}$ and $\rho_{b}$ are identified at 0.3 and 0.7 , respectively). Power is set at $90 \%$ and the value of alpha at 0.05 . The minimum sample size required based on formula (iii) and (iv) is as shown below:

Calculations:

$\alpha=0.05$

$\beta=0.1$

$k=10$

$\rho_{a}=0.3$

$\rho_{b}=0.7$

$\delta=\frac{(1-0.3)}{(1-0.7)}=2.3$

$n=\left[\frac{2\left(\frac{10}{10-1}+\frac{10}{10-1}\right)(1.96+1.282)^{2}}{\ln (2.3)^{2}}\right]+2$

$n=67.049 \approx 68$

Therefore, the minimum sample size required for this case study is approximately 68 samples per group.

\section{Results}

Based on pre-specified alpha, power and effect size, the minimum sample size requirements are shown in Table 2 to Table 3 . The pre-specified alpha and power are usually known (0.05 and $80.0 \%$ or $90.0 \%$, respectively) and thus, the minimum sample size required is mainly determined by the value of $k$ and the differences of the coefficients in null hypothesis and alternative hypothesis. The minimum requirement for sample size remains relatively unchanged when the value of $k$ increases. Larger sample size was observed when the differences between the coefficients in the null and alternative hypotheses were smaller.

For one coefficient of Cronbach's alpha test, if the coefficient of Cronbach's alpha equals to zero in the null hypothesis, it is possible to derive a smaller sample size of less than 30 to achieve a minimum desired effect size of 0.7 or more (Table 2). However, setting the coefficient of Cronbach's alpha larger than zero (e.g., $\mathrm{CAO}=0.50$ ) in the null hypothesis could be necessary in some cases and this will yield a larger sample size. (Table 2). For a comparison of two coefficients of Cronbach's alpha in different 
groups, a larger sample size is needed to detect smaller effect size when the coefficients in the null hypothesis $\left(\rho_{a}\right)$ and alternative hypothesis $\left(\rho_{b}\right)$ are nearly about the same (Table 3 ).

\section{Discussions}

For a single coefficient of Cronbach's alpha test, the application of the sample size tables can be used into two situations, which are sample size determination when CAo can be assumed equal to zero and sample size determination when CAo is assumed to be more than zero.

\section{Sample Size Determination for a Single Coefficient of Cronbach's Alpha Test when CAo can be Assumed Equal to Zero}

In the questionnaire reliability studies, the coefficient of Cronbach's alpha in the null hypothesis (CAo) is always assumed to be equaled to zero, implying that researchers assumed that there is no internal consistency of the whole items or for a particular domain of a questionnaire. Then, the coefficient of Cronbach's alpha in the alternative hypothesis (CA1) will assume that there is a magnitude of internal consistency (either low, moderate or strong) of the questionnaire or a particular domain of a questionnaire. The minimum sample size requirement depends on the desired magnitude of internal consistency in the alternative hypothesis.

Higher differences of Cronbach's alpha coefficients in the null hypothesis and alternative hypothesis will yield the lower sample size. Based on Table 2, in order to achieve an acceptable Cronbach's alpha of 0.7 , when the values of alpha and power are fixed at 0.05 and $80.0 \%$, respectively, the sample size ranges from four $(k=100$ and $\mathrm{CAO}=0.0$ versus $\mathrm{CA} 1=0.95)$ to $52(k=3$ and CAo $=0.0$ versus CA1 $=0.5)$, depending on the number of $k$ (number of items). Hence, Cronbach's alpha test is suitable for conducting pilot studies when the CAo is usually assumed to be zero. In studies related to questionnaire development and validation, Cronbach's alpha is a common indicator for internal consistency and has always been evaluated in the pilot studies (17-20).

Based on the calculation, it is possible that the sample size can be as small as four with assumption of a very high internal consistency such as 0.95 or more $(k=100$ and CAo $=0.0$ versus $\mathrm{CA} 1=0.95)$. Although researchers may target a high coefficient of Cronbach's alpha, however, it is impractical to do so as there is a possibility that it may not be achieved in an actual study. It is more reasonable to target a desired Cronbach's alpha between 0.7 to 0.8 with an acceptable sample size.

An example of a sample size statement is as followed: "The aim of the study is to evaluate the internal consistency of particular questionnaire "A". Questionnaire "A" has 15 items with a fivepoint Likert scale for every item. The coefficient of Cronbach's alpha in the null hypothesis and alternative hypothesis are assumed to be equal to 0.0 and 0.7 , respectively. Based on alpha value fixed at 0.05 , the minimum sample size requirement is 14 in order to achieve power of $80.0 \%$. The calculation is based on the formula introduced by Bonett (6)." If the questionnaire has a different number of items, researchers will need to calculate the sample size based on the formula in Equation (i).

\section{Sample Size Determination for a Single Coefficient of Cronbach's Alpha Test when CAo is Assumed to be More than Zero}

Hypothesis testing when CAo $>0$ is rare in literature. However, the concept of testing the null hypothesis with CAo > o may be useful in cases when researchers set a high target of internal consistency of an instrument. Some statistical soft-wares do not provide statistical test to assess internal consistency when CAo is assumed to be larger than zero. However, with the sample size calculation, researchers can calculate and determine the sufficient sample size to assess the internal consistency when CAo is assumed to be larger than zero.

For example, when $k=3$ and CAo $=0.50$, based on alpha $<0.05$ and power of at least $80.0 \%$, a minimum sample size of 31 is sufficient to detect $\mathrm{CA} 1$ at 0.80 . A larger minimum sample size is needed $(n=93)$ to detect CA1 at 0.70 (Table 2). An example of a sample size statement is as followed: "The aim of the study is to determine whether a particular questionnaire "B" has high magnitude of internal inconsistency. Questionnaire "B" has 10 items with a 5-point Likert scale for every item. The null hypothesis has set the coefficient of Cronbach's alpha is at 0.50 while in the alternative hypothesis, the coefficient of Cronbach's alpha is set at 0.80 . Based on alpha of 0.05 , the minimum sample size requirement is 23 to be able to detect at least $80.0 \%$ power of the test. The calculation is based on the formula introduced by Bonett (6)." 
Table 2. Sample size tables for Cronbach's alpha test with various effect sizes, alpha $=0.05$ and power are set to $80.0 \%\left(n^{a}\right)$ and $90.0 \%\left(n^{b}\right)$, respectively

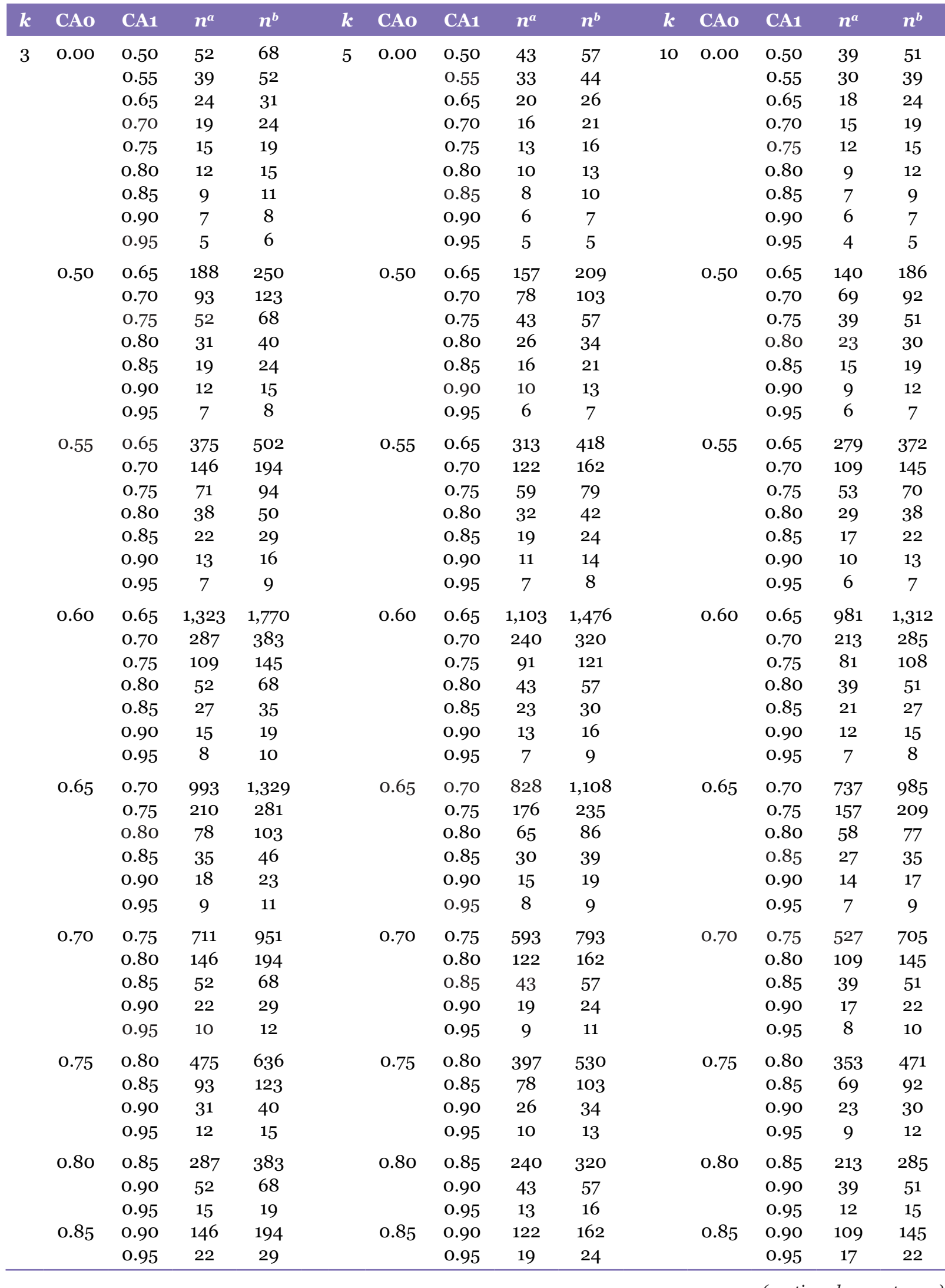


Original Article | Sample size for Cronbach's alpha

Table 2. (continued)

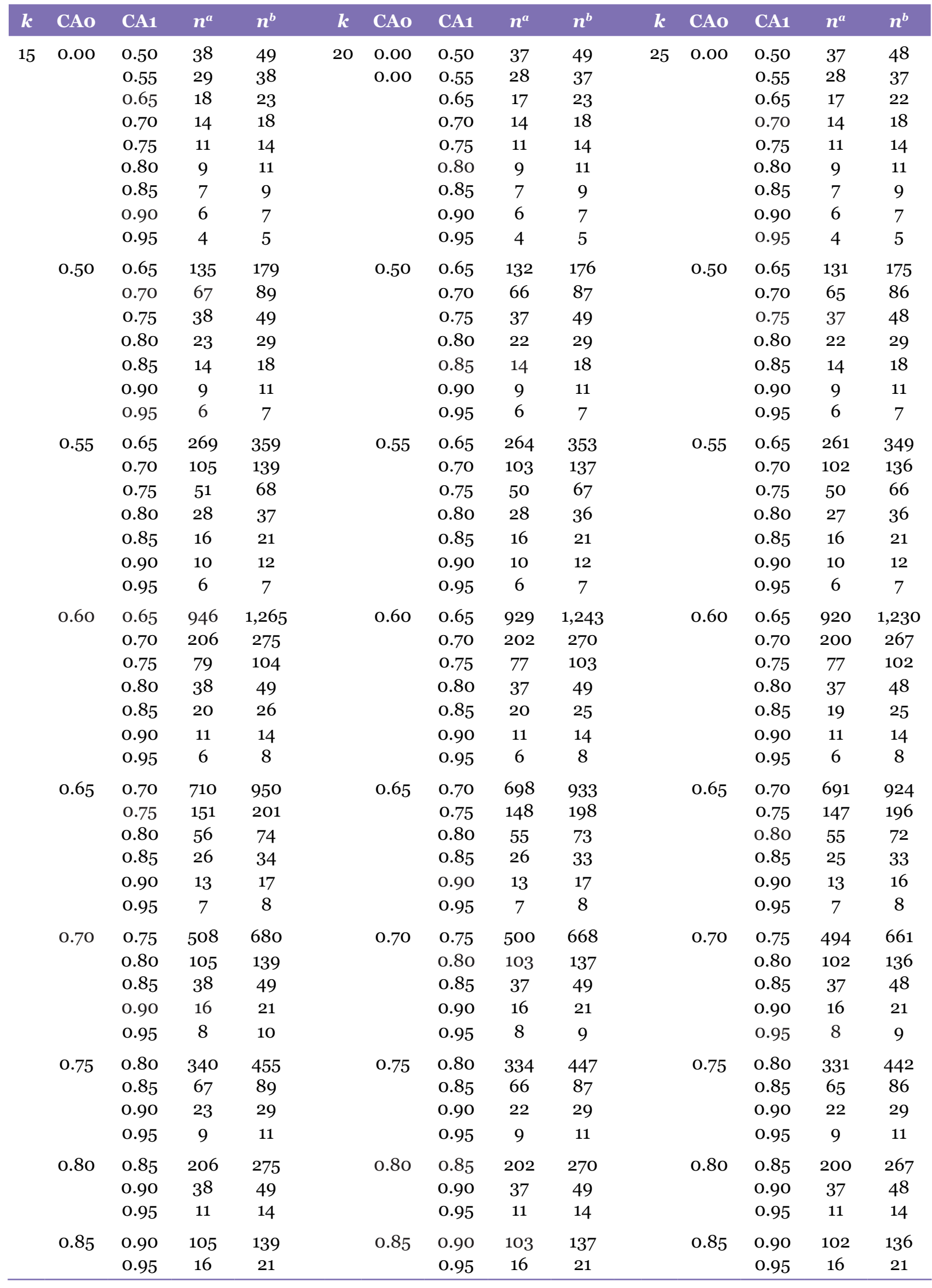


Table 2. (continued)

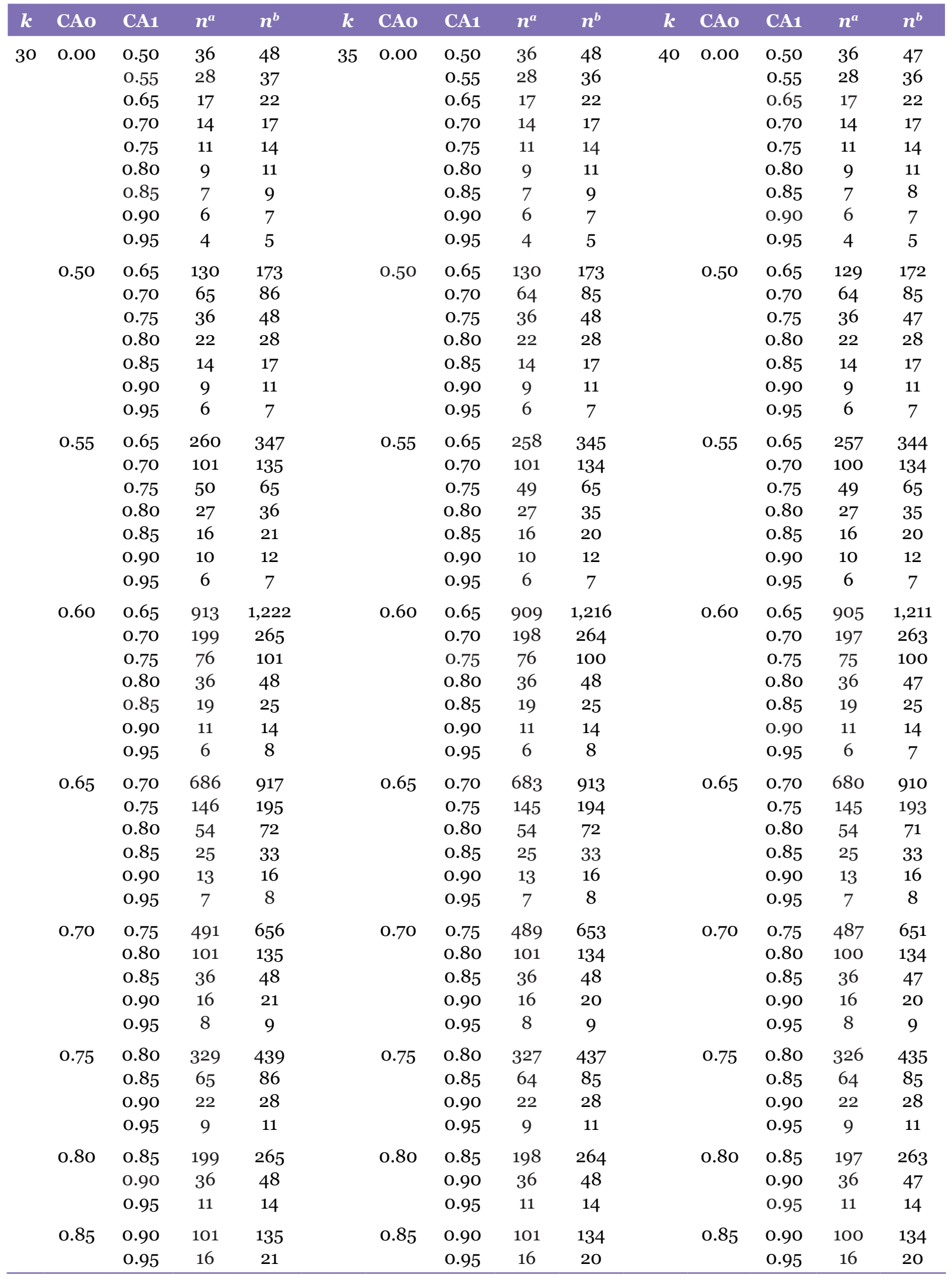


Original Article | Sample size for Cronbach's alpha

Table 2. (continued)

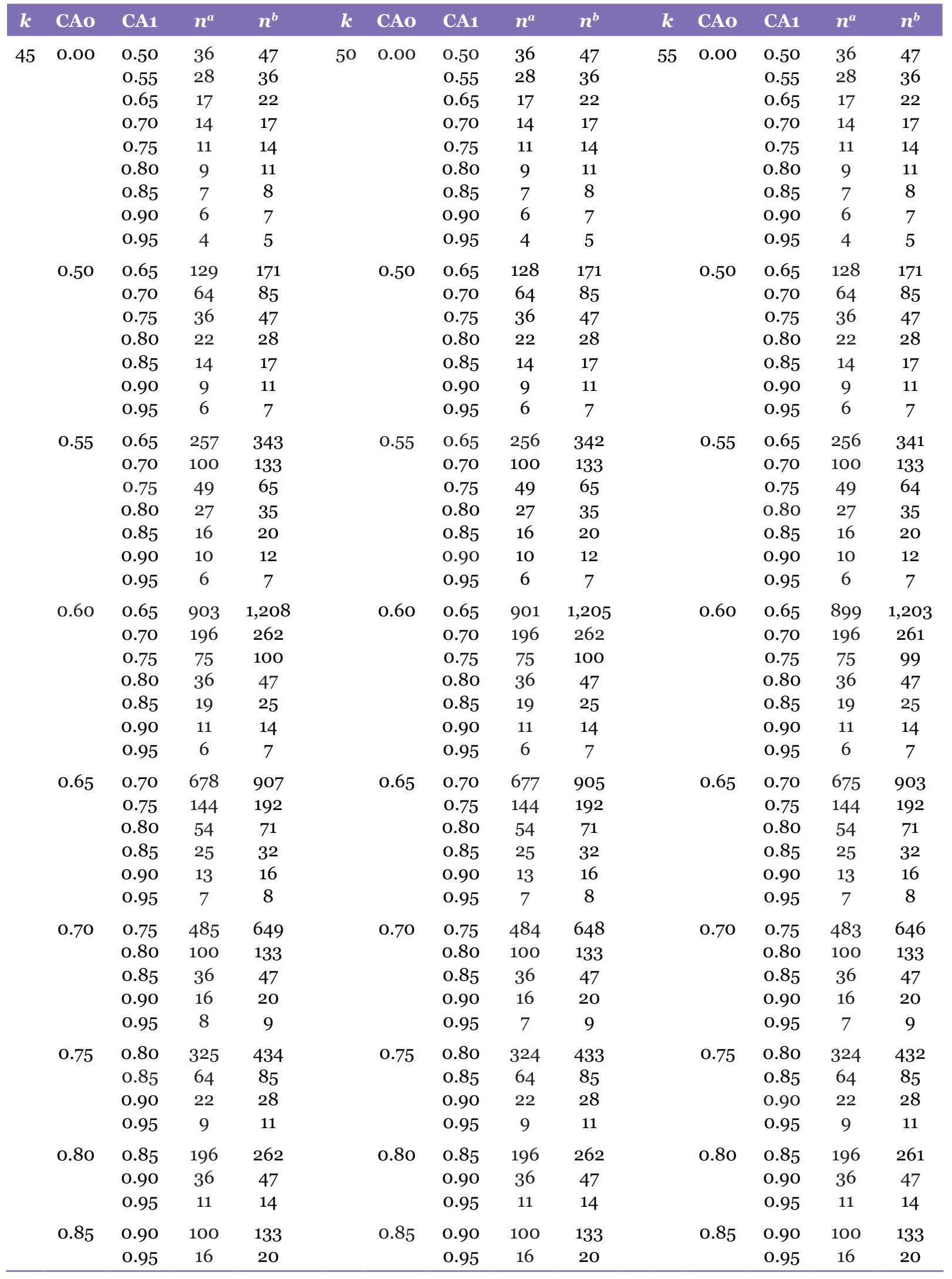


Table 2. (continued)




Original Article | Sample size for Cronbach's alpha

Table 2. (continued)

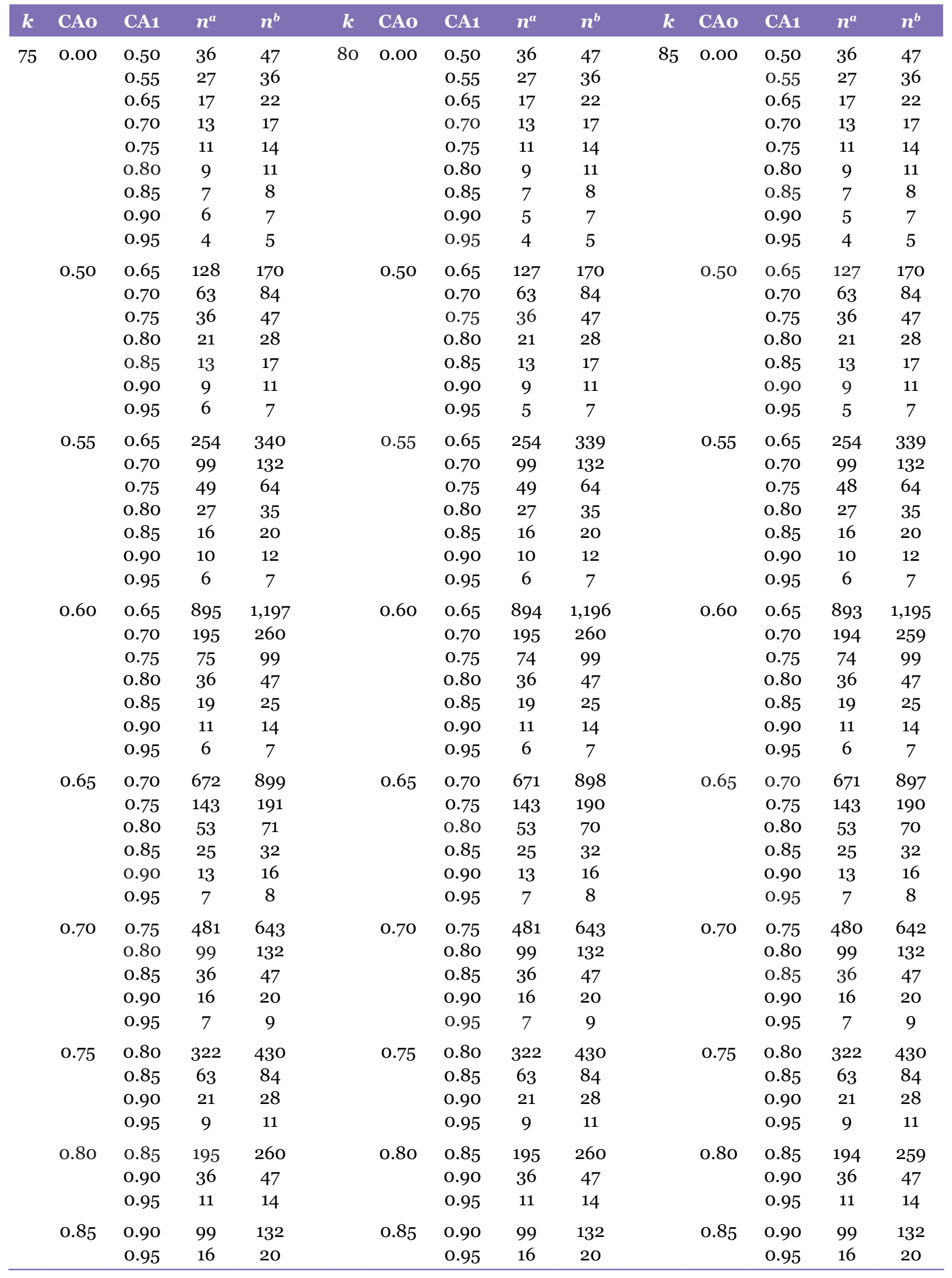


Table 2. (continued)

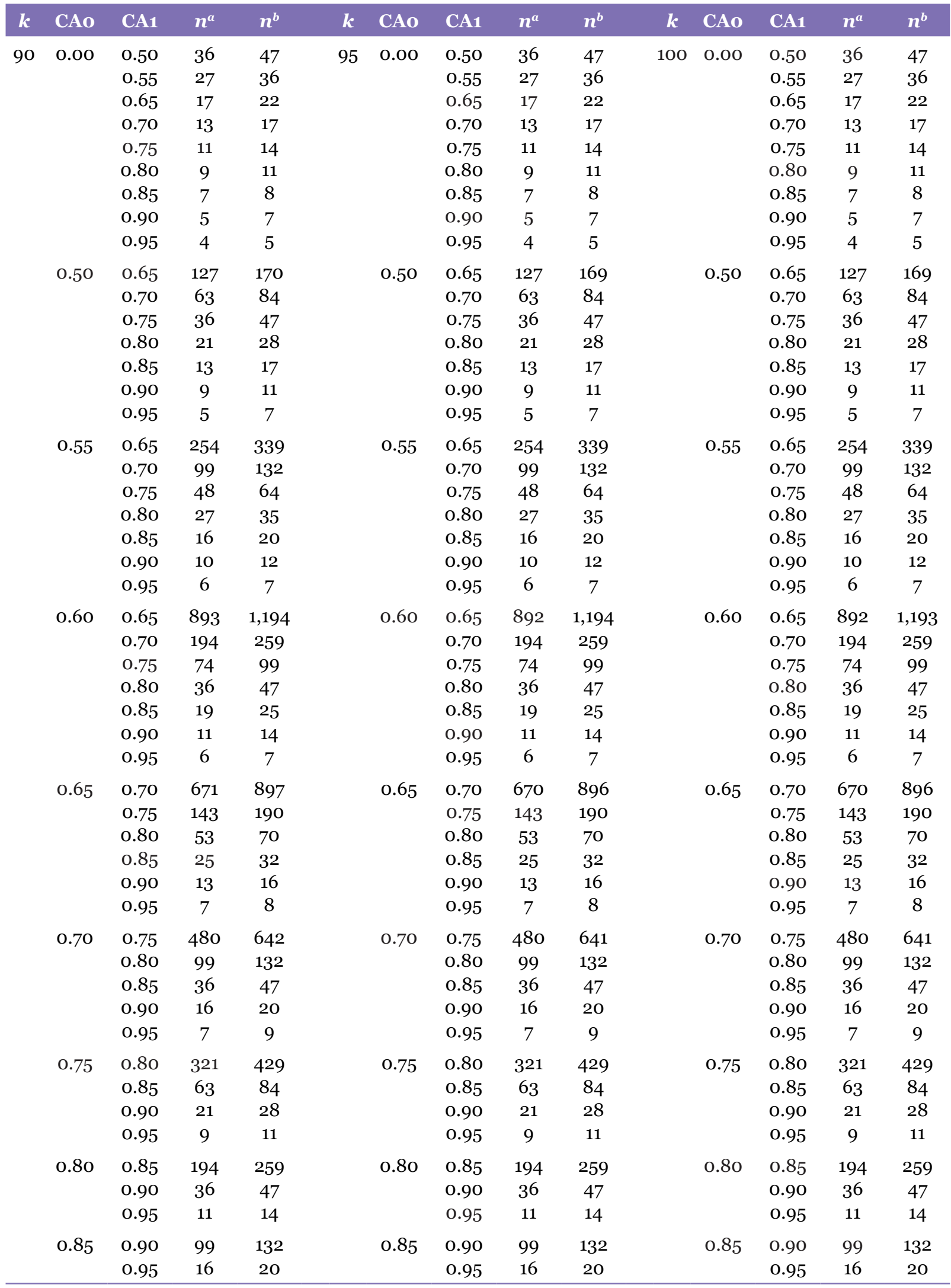


Original Article | Sample size for Cronbach's alpha

Table 3. Sample size tables for comparisons of two Cronbach's alpha test with various effect sizes, alpha $=0.05$ and power are set to $80.0 \%\left(n^{a}\right)$ and $90.0 \%\left(n^{b}\right)$, respectively

\begin{tabular}{|c|c|c|c|c|c|c|c|c|c|c|c|c|c|c|}
\hline $\boldsymbol{k}$ & $\rho^{a}$ & $\rho^{b}$ & $n^{a}$ & $n^{b}$ & $k$ & $\rho^{a}$ & $\rho^{b}$ & $n^{a}$ & $n^{b}$ & $\boldsymbol{k}$ & $\boldsymbol{\rho}^{a}$ & $\rho^{b}$ & $n^{a}$ & $n^{b}$ \\
\hline \multirow[t]{6}{*}{2} & 0.5 & 0.6 & 1264 & 1691 & \multirow[t]{6}{*}{8} & \multirow[t]{4}{*}{0.5} & 0.6 & 723 & 967 & \multirow[t]{6}{*}{30} & \multirow[t]{4}{*}{0.5} & 0.6 & 655 & 876 \\
\hline & & 0.7 & 243 & 325 & & & 0.7 & 140 & 187 & & & 0.7 & 127 & 169 \\
\hline & & 0.8 & 77 & 103 & & & 0.8 & 45 & 60 & & & 0.8 & 41 & 54 \\
\hline & & 0.9 & 27 & 35 & & & 0.9 & 16 & 21 & & & 0.9 & 15 & 19 \\
\hline & 0.7 & 0.8 & 384 & 514 & & \multirow[t]{2}{*}{0.7} & 0.8 & 221 & 295 & & \multirow[t]{2}{*}{0.7} & 0.8 & 200 & 267 \\
\hline & & 0.9 & 55 & 72 & & & 0.9 & 32 & 42 & & & 0.9 & 29 & 39 \\
\hline \multirow[t]{6}{*}{3} & 0.5 & 0.6 & 948 & 1269 & \multirow[t]{6}{*}{9} & \multirow[t]{4}{*}{0.5} & 0.6 & 712 & 952 & \multirow[t]{6}{*}{40} & \multirow[t]{4}{*}{0.5} & 0.6 & 649 & 868 \\
\hline & & 0.7 & 183 & 244 & & & 0.7 & 138 & 184 & & & 0.7 & 126 & 168 \\
\hline & & 0.8 & 59 & 78 & & & 0.8 & 45 & 59 & & & 0.8 & 41 & 54 \\
\hline & & 0.9 & 21 & 27 & & & 0.9 & 16 & 21 & & & 0.9 & 15 & 19 \\
\hline & 0.7 & 0.8 & 289 & 386 & & \multirow[t]{2}{*}{0.7} & 0.8 & 217 & 290 & & \multirow[t]{2}{*}{0.7} & 0.8 & 198 & 265 \\
\hline & & 0.9 & 42 & 55 & & & 0.9 & 32 & 42 & & & 0.9 & 29 & 38 \\
\hline \multirow[t]{6}{*}{4} & 0.5 & 0.6 & 843 & 1128 & \multirow[t]{6}{*}{10} & \multirow[t]{4}{*}{0.5} & 0.6 & 703 & 940 & \multirow[t]{6}{*}{50} & \multirow[t]{4}{*}{0.5} & 0.6 & 646 & 864 \\
\hline & & 0.7 & 163 & 217 & & & 0.7 & 136 & 181 & & & 0.7 & 125 & 167 \\
\hline & & 0.8 & 52 & 69 & & & 0.8 & 44 & 58 & & & 0.8 & 41 & 54 \\
\hline & & 0.9 & 19 & 24 & & & 0.9 & 16 & 21 & & & 0.9 & 15 & 19 \\
\hline & 0.7 & 0.8 & 257 & 343 & & \multirow[t]{2}{*}{0.7} & 0.8 & 215 & 287 & & \multirow[t]{2}{*}{0.7} & 0.8 & 197 & 263 \\
\hline & & 0.9 & 37 & 49 & & & 0.9 & 31 & 41 & & & 0.9 & 29 & 38 \\
\hline \multirow[t]{6}{*}{5} & 0.5 & 0.6 & 791 & 1058 & \multirow[t]{6}{*}{15} & 0.5 & 0.6 & 678 & 907 & 60 & 0.5 & 0.6 & 644 & 861 \\
\hline & & 0.7 & 153 & 204 & & & 0.7 & 131 & 175 & & & 0.7 & 125 & 166 \\
\hline & & 0.8 & 49 & 65 & & & 0.8 & 43 & 56 & & & 0.8 & 41 & 53 \\
\hline & & 0.9 & 18 & 23 & & & 0.9 & 15 & 20 & & & 0.9 & 15 & 19 \\
\hline & 0.7 & 0.8 & 241 & 322 & & 0.7 & 0.8 & 207 & 276 & & 0.7 & 0.8 & 197 & 262 \\
\hline & & 0.9 & 35 & 46 & & & 0.9 & 30 & 40 & & & 0.9 & 29 & 38 \\
\hline 6 & 0.5 & 0.6 & 759 & 1015 & 20 & 0.5 & 0.6 & 666 & 891 & 70 & 0.5 & 0.6 & 642 & 859 \\
\hline & & 0.7 & 147 & 196 & & & 0.7 & 129 & 172 & & & 0.7 & 125 & 166 \\
\hline & & 0.8 & 47 & 63 & & & 0.8 & 42 & 55 & & & 0.8 & 40 & 53 \\
\hline & & 0.9 & 17 & 22 & & & 0.9 & 15 & 20 & & & 0.9 & 15 & 19 \\
\hline & 0.7 & 0.8 & 232 & 309 & & 0.7 & 0.8 & 204 & 272 & & 0.7 & 0.8 & 196 & 262 \\
\hline & & 0.9 & 34 & 44 & & & 0.9 & 30 & 39 & & & 0.9 & 29 & 38 \\
\hline 7 & 0.5 & 0.6 & 738 & 987 & 25 & 0.5 & 0.6 & 659 & 882 & 80 & 0.5 & 0.6 & 641 & 857 \\
\hline & & 0.7 & 143 & 190 & & & 0.7 & 128 & 170 & & & 0.7 & 124 & 166 \\
\hline & & 0.8 & 46 & 61 & & & 0.8 & 41 & 55 & & & 0.8 & 40 & 53 \\
\hline & & 0.9 & 17 & 21 & & & 0.9 & 15 & 19 & & & 0.9 & 15 & 19 \\
\hline & 0.7 & 0.8 & 225 & 301 & & 0.7 & 0.8 & 201 & 269 & & 0.7 & 0.8 & 196 & 261 \\
\hline & & 0.9 & 33 & 43 & & & 0.9 & 30 & 39 & & & 0.9 & 29 & 38 \\
\hline
\end{tabular}

The present article recommends testing hypothesis with CAo $=0.5$ is necessary to test whether an instrument has an excellent internal consistency. However, it is a choice by the researchers to set the value of CAo, including setting CAo as equals to zero. But, solely targeting a large difference of Cronbach's alphas between CAo and CA1 to get a lower sample size is not recommended. Therefore, justification is needed whether testing such effect size is scientifically necessary.

\section{Sample Size Determination when to Compare Two Cronbach's Alpha in Two Different Groups}

Hypothesis testing to compare two Cronbach's alphas in two different groups is also rare in literature. However, this hypothesis testing is useful if the researcher aims to compare two coefficients of Cronbach's alphas in two different groups. Although some statistical softwares might not provide statistical test to assess such hypothesis, researchers can calculate and determine sufficient sample size for the planned study to compare two Cronbach's alphas in two different groups. 
For example, when $k=3$ and $\rho_{a}=0.50$, based on alpha $=0.05$ and power $=80.0 \%$, a minimum sample size of 183 is sufficient to detect $\rho_{b}$ at 0.70 . A lower minimum sample size is needed $(n=59)$ to detect $\rho_{b}$ at 0.80 (Table 2). An example of a sample size statement is as followed: "The aim of the study is to determine whether the internal consistency of particular questionnaire "B" in group "two" is higher than in group "one". Questionnaire "B" has 15 items with a 5-point Likert scale for every item. The coefficient of Cronbach's alpha in group "one" was reported at 0.70 while the coefficient of Cronbach's alpha in group "two" is hypothesised to be at least 0.80 . Based on alpha of 0.05 , the minimum sample size requirement is 207 to be able to detect at least $80.0 \%$ power of the test. The calculation is based on the formula introduced by Bonett (12).”

\section{Conclusion}

This article provides sample size tables and simple guides for sample size estimation for Cronbach's alpha. This guideline is useful for researchers especially in medical field where the recommended tables will ease them in estimating sample size for reliability studies. For one coefficient of Cronbach's alpha test, the assumption of "the CAo equals to zero" will usually yield a smaller sample size, and that is appropriate for pilot studies. However, to ensure an instrument has an excellent internal consistency, testing the hypothesis with CAo larger than zero (CAO $>0$ ), such as $\mathrm{CAO}=0.5$ is recommended.

Besides that, the calculation of sample size based on comparing two Cronbach's alpha values in two different groups is also presented. Justifications are needed to decide whether the testing for extremely low or extremely large effect sizes are scientifically necessary. Hopefully, this guideline could help the researchers in sample size estimation for their researches to assess the reliability of an instrument.

\section{Acknowledgements}

We would like to thank the Director General of Health Malaysia for his permission to publish this article. We would also like to thank Dr Lee Keng Yee for her effort in proofreading the manuscript and Ms Chien Joo Lim for processing the manuscript for publication.

\section{Conflicts of Interest}

None.

\section{Funds}

None.

\section{Authors' Contributions}

Conception and design: MAB

Analysis and interpretation of the data: MAB, EDO, NAB

Drafting of the article: MAB, EDO, NAB

Critical revision of the article for important intellectual content: MAB, EDO, NAB

Final approval of the article: MAB, EDO, NAB

Statistical expertise: MAB, EDO, NAB

\section{Correspondence}

Dr Mohamad Adam Bujang

Research Officer

BSc (Hons) Statistics (Universiti Teknologi MARA), MBA (Universiti Teknologi MARA),

PhD (IT and Quantitative Sciences) (Universiti

Teknologi MARA)

Clinical Research Centre, Sarawak General Hospital, Ministry of Health, Jalan Tun Ahmad Zaidi Adruce, 93586 Kuching, Sarawak, Malaysia.

Tel: +6082276820

Fax: +6082 276823

E-mail: adam@crc.gov.my

\section{References}

1. Cronbach, LJ. Coefficient alpha and the internal structure of tests. Psychometrika. 1951;16(3):297-334. https://doi.org/10.1007/ BFo2310555

2. Gliem JA, Gliem RR. Calculating, interpreting, and reporting Cronbach's alpha reliability coefficient for Likert-type scales. Midwest Research-to-Practice Conference in Adult, Continuing, and Community Education. 2003. Retrieved from https://scholarworks.iupui.edu/ bitstream/handle/1805/344/Gliem+\&+Gliem.pdf? sequence $=1$.

3. Leontitsis A, Pagge J. A simulation approach on Cronbach's alpha statistical significance. Math Comput Simul. 2007;73(5):336-340. https:// doi.org/10.1016/j.matcom.2006.08.001 
Original Article | Sample size for Cronbach's alpha

4. Lovibond SH, Lovibond PF. Manual for the depression anxiety stress scales. 2nd ed. Sydney: Psychology Foundation; 1995.

5. Berg KO, Wood-Dauphinee SL, Williams JT, et al. Measuring balance in the elderly: validation of an instrument. Can J Public Health. 1992;83(2):S7S11.

6. Bonett, DG. Sample size requirements for testing and estimating coefficient alpha. $J$ Educ Behav Stat. 2002;27(4):335-340. https://doi. org/10.3102/10769986027004335

7. Green S, Lissitz R, Mulaik S. Limitations of coefficient alpha as an index of test unidimensionlity. Educ Psychol Meas. 1977;37(4):827-838. https://doi.org/10.1177/ 001316447703700403

8. Cortina J. What is coefficient alpha: an examination of theory and applications. $J \mathrm{Appl}$ Psychol. 1993;78(1):98-104. https://doi.org/10. 1037/0021-9010.78.1.98

9. Schmitt N. Uses and abuses of coefficient alpha. Psychol Assess. 1996;8(4):350-353. https://doi. org/10.1037/1040-3590.8.4.350

10. Bland J, Altman D. Statistics notes: Cronbach's alpha. BMJ. 1997;314:572. https://doi.org/10. $1136 /$ bmj.314.7080.572

11. Streiner D. Starting at the beginning: an introduction to coefficient alpha and internal consistency. J Pers Assess. 2003;80(1):99-103. https://doi.org/10.1207/S15327752JPA8001_18

12. Bonett, DG. Sample size requirements for comparing two alpha reliability coefficients. Appl Psychol Meas. 2003;27(1):235-240. https://doi. org/10.1177/0146621602239477

13. Yurdugül H. Minimum sample size for Cronbach's coefficient alpha: a Monte Carlo study. Hacettepe Egitim Dergisi. 2008;35:397-405.
14. Bonett DG, Wright TA. Cronbach's alpha reliability: interval estimation, hypothesis testing, and sample size planning. J Organ Behav. 2015;36(1):3-15. https://doi.org/10.1002/job.1960

15. Conroy, R. Sample size: a rough guide. Ethics (Medical Research) Committee; 2015. Retrieved from: http://www.beaumontethics.ie/docs/ application/samplesizecalculation.pdf.

16. Samuels P. Statistical methods-scale reliability analysis with small samples. Birmingham: Birmingham City University, Centre for Academic Success; 2015.

17. Jalaludin MY, Fuziah MZ, Hong JYH, Mohamad Adam B, Jamaiyah H. Reliability and validity of the revised summary of diabetes self-care activities (SDSCA) for Malaysian children and adolescents. Malaysian Family Physician. 2012;7(2-3):10-20.

18. Jalaludin MY, Fuziah MZ, Hadhrami MZ, Hong JYH, Mohamad Adam B, Jamaiyah H. Reliability and validity of the Malay translated version of diabetes quality of life for youth questionnaire. Malaysian Family Physician. 2013;8(1):12-19.

19. Bujang MA, Ismail $M$, Mohd Hatta NKB, Baharum N, Othman SS, Mat Lazim SS, Shah SA. Malaysian Journal of Public Health Medicine. 2016;16(3):227-234.

20. Bujang MA, Ismail M, Mohd Hatta NKB, Othman SH. Baharum N, Mat Lazim SS. Validation of the Malay version of Diabetes Quality of Life (DQOL) Questionnaire for adult population with type 2 diabetes mellitus. Malays $\mathrm{J}$ Med Sci. 2017;24(4):86-96. https://doi.org/10.21315/ mjms2017.24.4.10 